\title{
Three years of routine Raman lidar measurements of tropospheric aerosols: Backscattering, extinction, and residual layer height
}

\author{
J. Schneider ${ }^{1, *}$ and R. Eixmann ${ }^{1}$ \\ ${ }^{1}$ Leibniz-Institute for Atmospheric Physics at Rostock University, Kühlungsborn, Germany \\ * present address: Cloud Physics and Chemistry Department, Max Planck Institute for Chemistry, Mainz, Germany
}

Received: 25 October 2001 - Published in Atmos. Chem. Phys. Discuss.: 18 January 2002

Revised: 5 June 2002 - Accepted: 24 October 2002 - Published: 13 November 2002

\begin{abstract}
We have performed a three-year series of routine lidar measurements at preselected times. The measurements were performed between 1 December 1997, and 30 November 2000, at Kühlungsborn, Germany $\left(54^{\circ} 07^{\prime} \mathrm{N}, 11^{\circ} 46^{\prime} \mathrm{E}\right)$. Using a Rayleigh/Mie/Raman lidar system, we measured the aerosol backscatter coefficients at three wavelengths and the extinction coefficient at one wavelength. The present data analysis focuses on after-sunset Raman measurements obtained on cloud-free days. Aerosol backscatter profiles are available for altitudes above $100 \mathrm{~m}$, while the majority of the extinction measurements has been restricted to heights above the residual layer. The residual layer shows an annual cycle with its maximum height in summer $(2000 \mathrm{~m})$ and minimum height in winter $(850 \mathrm{~m})$. The backscatter coefficients in the residual layer were found to be about 10 times higher than above. The mean aerosol optical depth above the residual layer and below $5 \mathrm{~km}$ is $0.3( \pm 1.0) \times 10^{-2}$ in summer, and $1.5( \pm 1.0) \times 10^{-2}$ in winter, which almost is negligible compared to values measured in during daytime in the planetary boundary layer. A cluster analysis of the backward trajectories yielded two major directions of air mass origin above the residual layer and 4 major directions inside. A marked difference between the aerosol properties dependent on the air mass origin could be found for air masses originating from the west and travelling at high wind speeds. Comparing the measured spectral dependence of the backscatter coefficients with data from the Global Aerosol Data Set, we found a general agreement, but only a few conclusions with respect to the aerosol type could be drawn due to the high variability of the measured backscatter coefficients.
\end{abstract}

Correspondence to: J. Schneider

(schneider@mpch-mainz.mpg.de)

\section{Introduction}

For the assessment of the climatic impact of aerosols (aerosol forcing) the knowledge of both the temporal and vertical distribution of the aerosol is essential. Unlike greenhouse gases, aerosols are short-lived and therefore their influence is restricted to regional scales. Their radiative properties are dependent on their size and their chemical composition. Aerosol particles containing absorbing material (e.g. soot) can lead to a warming of the atmosphere, while nonabsorbing particles reflect incoming radiation back into space and thereby lead to a negative climate forcing (e.g. Seinfeld and Pandis, 1998). The tropospheric aerosol particles are to a large extend concentrated in the well-mixed planetary boundary layer (PBL), which develops through the day driven by convection to its maximum extent at around 14:00 local solar time. After sunset, the remainder of the boundary layer, the so-called residual layer, keeps stable until sunrise. Without the knowledge of the height of this layer and the optical properties of the particles contained in this layer, assessment of aerosol forcing suffers from great uncertainties (e.g. Penner et al., 2001).

Lidar can provide vertically resolved measurements of extinction and backscatter coefficients and thereby the height of the PBL or the night-time residual layer. If these data are obtained at different wavelengths, the microphysical properties (size distribution, refractive index) can be estimated (inversion). However, the retrieval of these optical properties by conventional backscatter lidar suffers from the well known problem that two quantities are calculated from only one measured signal. Therefore, the so-called lidar ratio, i.e. the ratio between aerosol extinction and backscatter coefficient, is needed as an input parameter (e.g. Klett, 1981, 1985; Fernald, 1984). This lidar ratio is usually height- and aerosol type-dependent and can only roughly be estimated for individual measurements. The error introduced by assuming a 


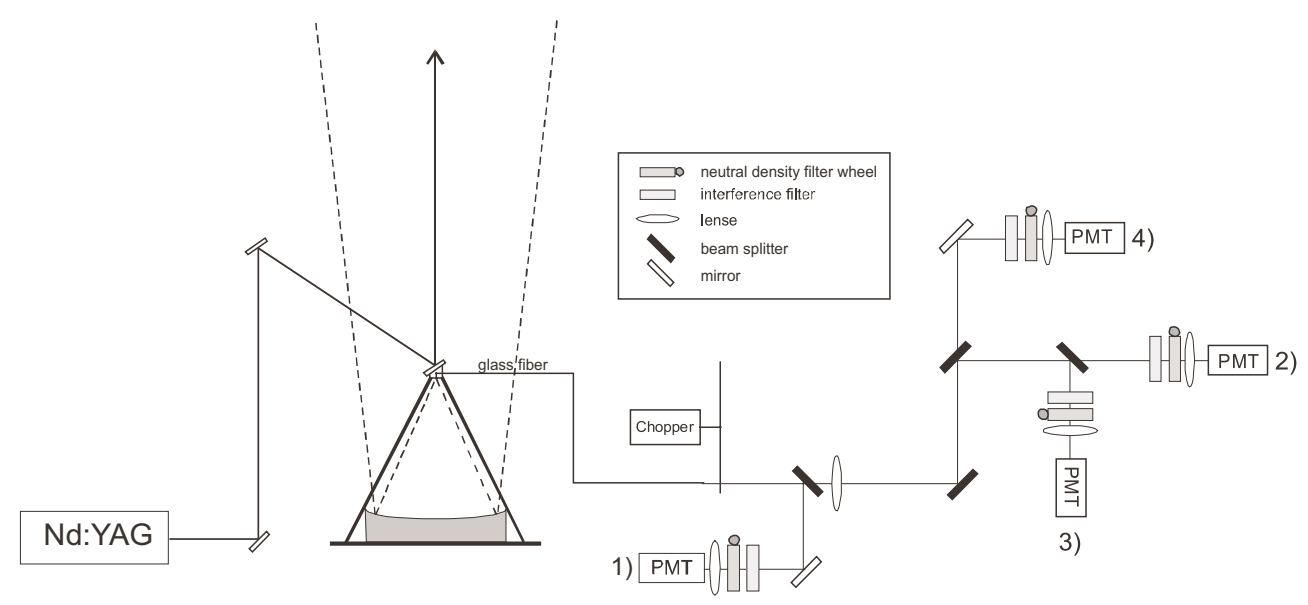

Fig. 1. Setup of the IAP RMR lidar. Only the detection channels used in this work are shown. Technical details are given in Table 1. PMT: Photomultiplier tube

height-independent lidar ratio was thoroughly discussed by Sasano et al. (1985). Different lidar approaches have been introduced to overcome these disadvantages. These methods include the high spectral resolution lidar (HSRL), the scanning lidar, and the Raman lidar. The high resolution lidar separates the molecular scattering from the aerosol scattering by the use of very narrow optical filters. Since this technology is rather demanding, it is implemented only at a few sites worldwide (e.g. Grund and Eloranta, 1991). The scanning lidar technique measures the backscatter signal under different angles. Here the disadvantage lies in the necessary assumption of horizontal homogeneity (Gutkowicz-Krusin, 1993). The Raman method that is used here uses a second, independent molecular backscatter signal, as for example the Raman-shifted nitrogen backscatter signal. This technique allows the independent determination of the aerosol extinction coefficient (Ansmann et al., 1990, 1992). Furthermore, the backscatter coefficient is determined from the ratio of two return signal which leads to independence of the requirement of a full overlap between laser beam and telescope field-ofview. Due to the low intensity of the Raman scattering, this technique is usually restricted to night-time, when the background from the sky is low enough.

Since 1 December 1997, the department "Optical Soundings" at the Leibniz Institute for Atmospheric Physics (IAP) at Kühlungsborn, Germany, performs routine lidar measurements within the German Lidar Network (Bösenberg et al., 1998, 2001a) and its follow-up project, EARLINET (European Aerosol Lidar Research Network) (Bösenberg et al., 2001b). Major goal of both projects is the establishment of an unbiased climatological data set characterizing the vertical distribution of optical aerosol parameters at selected sites. This goal requires random sampling which is not correlated with particular weather situations. To achieve this the routine measurements are performed at preselected times independent from atmospheric conditions. The measured profiles are averaged over at least thirty minutes to reduce the influence of small scale variability. Here, we report the results of the first three years of routine operation at Kühlungsborn $\left(54^{\circ} \mathrm{N}, 12^{\circ} \mathrm{E}\right)$, focusing on the Raman measurements after sunset.

\section{Measurements}

\subsection{System description}

The Rayleigh/Mie/Raman (RMR) lidar at IAP Kühlungsborn uses a Nd:YAG laser system (Spectra Physics GCR 290) emitting at the fundamental $(1064 \mathrm{~nm})$ and the second and third harmonic (532 and $355 \mathrm{~nm}$ ). Detected signals include the three emitted wavelength plus the nitrogen Raman shifted return signals at 607 and $387 \mathrm{~nm}$. Additionally, the vertical depolarized return signal at $532 \mathrm{~nm}$ is detected. All signals are detected with $50 \mathrm{~m}$ vertical resolution. The receiver site consists of two telescopes $(50 \mathrm{~cm}$ diameter each) of which the first is mounted coaxially to the laser beam and is used for detection of the $355 \mathrm{~nm}, 532 \mathrm{~nm}, 1064 \mathrm{~nm}$, and the $607 \mathrm{~nm}$ Raman signal. Full geometric overlap is reached at $1000 \mathrm{~m}$, approximately. The second is mounted off-axis and is used for the $387 \mathrm{~nm}$ and the depolarized signal. Here, full geometric overlap is reached only at $2000 \mathrm{~m}$, which is in general above the planetary boundary layer. For this reason, no $387 \mathrm{~nm}$ data were included in the present work. In the meantime, the $387 \mathrm{~nm}$ channel has also been included into the coaxial telescope. The system is located at Kühlungsborn, Germany $\left(54^{\circ} 07^{\prime} \mathrm{N}, 11^{\circ} 46^{\prime} \mathrm{E}\right)$, in a rural environment near the shore of the Baltic Sea, and is in operation since June 1997 (Alpers et al., 1999). A schematic of the setup, showing only the components used for this work, is given in Fig. 1. In the detection branch the wavelengths are separated by dichroic beam splitters, filtered using interference 
Table 1. Technical data of the IAP RMR Lidar

\begin{tabular}{llll}
\hline Transmitter & & Receiver & \\
\hline Laser type & seeded Nd:YAG & Telescope type & parabolic \\
Wavelengths & $355,532,1064 \mathrm{~nm}$ & Focal lengths & $120 \mathrm{~cm}$ \\
Pulse energies & $200,400,500 \mathrm{~mJ}$ & Active diameter & $50 \mathrm{~cm}$ \\
Repetition rates & $30 \mathrm{pps}$ & Fibre diameter & $1 \mathrm{~mm}$ \\
Pulse lengths & $10,13,18 \mathrm{nsec}$ & Num. Aperture & 0.22 \\
& & Field-of-view & $0.83 \mathrm{mrad}$ \\
\hline
\end{tabular}

Detection channels

\begin{tabular}{lllll}
\hline Channel No. & 1 & 2 & 3 & 4 \\
\hline Interference filters & & & & \\
Central wavelength & 354.61 & 532.09 & 607.44 & 1064.14 \\
$\begin{array}{l}\text { Full width at half max. } \\
\text { Transmission }\end{array}$ & 0.92 & 0.32 & 0.36 & 1.02 \\
Manufacturer & $44 \%$ & $64 \%$ & $69 \%$ & $76 \%$ \\
Photomultipliers & BARR & BARR & BARR & BARR \\
\hline $\begin{array}{l}\text { Manufacturer } \\
\text { Type }\end{array}$ & Hamamatsu & Hamamatsu & Hamamatsu & Hamamatsu \\
& $4220 \mathrm{P}$ (selected) & $4632 \mathrm{P}$ (selected) & $4632 \mathrm{P}$ (selected) & R3236 (selected), \\
Data acquisition mode & $100 \mathrm{MHz}$ photon & $100 \mathrm{MHz}$ photon & $\begin{array}{l}100 \mathrm{MHz} \text { photon } \\
\text { counting }\end{array}$ & $\begin{array}{l}100 \mathrm{MHz} \text { photon } \\
\text { counting }\end{array}$ \\
\hline
\end{tabular}

filters (Barr Associates, Inc.), and detected by photomultiplier tubes. Technical data of the system are summarized in Table 1.

\subsection{Determination of the aerosol optical parameters}

Calculation of the extinction coefficient from the Raman signals follows the method described by Ansmann et al. (1990, 1992). The aerosol extinction coefficient $\alpha_{\lambda_{0}}^{\text {aer }}$ at the emitted wavelength $\lambda_{0}$ is given by:

$\alpha_{\lambda_{0}}^{\mathrm{aer}}(z)=\frac{-\frac{d}{d z} \ln \left(P_{\lambda_{R}}^{\mathrm{corr}}(z)\right)}{1+\left(\frac{\lambda_{0}}{\lambda_{R}}\right)^{k}}$

where $P_{\lambda_{R}}^{\text {corr }}(z)$ is the detected signal corrected for range, $\mathrm{N}_{2}$ number density, and molecular extinction:

$$
P_{\lambda_{R}}^{\text {corr }}(z)=\frac{P_{\lambda_{R}}(z) z^{2}}{N_{R}(z) \exp \left(-\int_{0}^{z}\left[\alpha_{\lambda_{0}}^{m o l}(\zeta)+\alpha_{\lambda_{R}}^{\text {mol }}(\zeta)\right] d \zeta\right)}(2)
$$

with:

$$
\begin{aligned}
& \lambda_{0}: \quad \text { emitted wavelength } \\
& \lambda_{R}: \quad \text { Raman shifted wavelength } \\
& z: \quad \text { altitude } \\
& P_{\lambda_{R}}(z) \text { : received Raman backscatter signal from } \\
& \text { the altitude } z \text {, } \\
& N_{R}(z) \text { : number density of Raman scatterers, here } \\
& \mathrm{N}_{2} \text { molecules } \\
& \alpha_{\lambda_{0}}^{\text {mol }}, \alpha_{\lambda_{R}}^{\text {mol }}: \text { molecular extinction at } \lambda_{0} \text { and } \lambda_{R} \text {, respec- } \\
& \text { tively. }
\end{aligned}
$$

This method allows one to determine the extinction coefficient independently, with the only necessary assumption of the wavelength dependence of the aerosol extinction coefficient

$\alpha_{\mathrm{aer}}(\lambda) \sim \lambda^{-k}$

Since the ratio between emitted and Raman shifted wavelengths is close to unity, deviations of this assumption do not contribute significantly to the error. Observations indicate that $k$ varies between 0 and 2 (Ferrare et al., 1998). For large particles, e.g. cirrus clouds, $k$ equals zero (Ansmann et al., 1992). Usually, $k=1$ is assumed for all measurements except for cirrus clouds, where $k=0$ is chosen. To obtain the nitrogen molecule number density and 
the Rayleigh scattering coefficients $\alpha_{\lambda_{0}}^{\mathrm{mol}}$ and $\alpha_{\lambda_{R}}^{\mathrm{mol}}$, air temperature, density, and relative humidity are available from local radiosonde measurements, performed by the German Weather Service (DWD) on a regular basis. Radiosonde data are available at noon and midnight from two stations, one located $120 \mathrm{~km}$ east (Greifswald), the other located 150 northwest (Schleswig). Additionally, on certain occasions radiosondes can be launched at IAP Kühlungsborn. For days where no radiosonde data were available, the US Standard Atmosphere was used. In order to calculate the derivative

$\frac{d}{d z}\left[\ln \left(P R^{2}\right)\right]$

the received Raman signal has to be averaged in time and altitude. To reduce the influence of small scale variability, a minimum time interval of $30 \mathrm{~min}$ (approximately 54000 laser shots) was chosen by the participants of the lidar networks. Typical height intervals are: $200 \mathrm{~m}$ (4 channels) between 1 and $5 \mathrm{~km}, 500 \mathrm{~m}$ between 5 and $10 \mathrm{~km}$, and $1000 \mathrm{~m}$ above $10 \mathrm{~km}$. These values are subject to change dependent on the actual shape of the lidar return signal, the averaged time interval and thereby the total count rate. Since the method is based on the absolute lidar return signal, it can only be applied above the height at which the laser beam and the telescope field-of-view fully overlap. This reduces our data to altitudes above $1 \mathrm{~km}$, thereby excluding most of the boundary/residual layer. Once the aerosol extinction coefficient is known, the aerosol backscatter coefficient can be determined from the following equation:

$$
\begin{aligned}
\beta_{\lambda_{0}}^{\mathrm{aer}}(z)=-\beta_{\lambda_{0}}^{\mathrm{mol}}(z)+\left[\beta_{\lambda_{0}}^{\mathrm{aer}}\left(z_{0}\right)+\beta_{\lambda_{0}}^{\mathrm{mol}}\left(z_{0}\right)\right] \\
\times \frac{P_{\lambda_{R}}^{\mathrm{corr}}\left(z_{0}\right) P_{\lambda_{0}}^{\mathrm{corr}}(z)}{P_{\lambda_{0}}^{\mathrm{corr}}\left(z_{0}\right) P_{\lambda_{R}}^{\mathrm{corr}}(z)} \times \frac{\exp \left[-\int_{z_{0}}^{z} \alpha_{\lambda_{R}}^{\mathrm{aer}}(\zeta) d \zeta\right]}{\exp \left[-\int_{z_{0}}^{z} \alpha_{\lambda_{0}}^{\mathrm{aer}}(\zeta) d \zeta\right]}
\end{aligned}
$$

with

$$
P_{\lambda_{0}}^{\text {corr }}(z)=\frac{P_{\lambda_{0}}(z) z^{2}}{\exp \left(-2 \int_{0}^{z}\left[\alpha_{\lambda_{0}}^{\text {mol }}(\zeta)\right] d \zeta\right)}
$$

and

$$
\begin{array}{ll}
P_{\lambda_{0}}(z): & \begin{array}{l}
\text { received backscatter signal at } \lambda_{0} \text { from the } \\
\text { altitude } z,
\end{array} \\
\beta_{\lambda_{0}}^{\text {mol }}(z): \begin{array}{l}
\text { molecular backscatter coefficient at } \lambda_{0} \text { at } \\
\text { altitude } z,
\end{array} \\
z_{0}: & \text { reference height. }
\end{array}
$$

The reference height $z_{0}$ is usually chosen in a way that $\beta_{\lambda_{0}}^{\text {aer }}\left(z_{0}\right) \ll \beta_{\lambda_{0}}^{\text {mol }}\left(z_{0}\right)$. At $355 \mathrm{~nm}$ and $532 \mathrm{~nm}$, this condition can be met by seeking the local minimum of the ratio $\beta_{\lambda_{0}}^{\text {aer }}\left(z_{0}\right) / \beta_{\lambda_{0}}^{\text {mol }}\left(z_{0}\right)$ which is usually found in the upper troposphere around 6 to $8 \mathrm{~km}$, and then setting $\beta_{\lambda_{0}}^{\text {aer }}\left(z_{0}\right)$ to zero. At $1064 \mathrm{~nm}$, however, this condition is rather hard to find. Possible ways to calibrate the $1064 \mathrm{~nm}$ signal include comparison with column optical thickness measured by sun photometer or using a cirrus cloud with neutral scattering properties as a reference point. Since our site does not operate a sun photometer, we chose the following procedure: For the day where cirrus clouds were present, we chose the same reference height $z_{0}$ as for $\beta_{532}^{\text {aer }}$ and $\beta_{355}^{\text {aer }}$, and adjusted $\beta_{1064}^{\text {aer }}\left(z_{0}\right)$ in a way that the neutral scattering properties of the cirrus clouds were reproduced. It turned out that, even though the reference height varied between 4 and $8 \mathrm{~km}$, the "background" backscatter ratio

$\frac{\beta_{1064}^{\text {aer }}\left(z_{0}\right)+\beta_{1064}^{\text {mol }}\left(z_{0}\right)}{\beta_{1064}^{\text {mol }}\left(z_{0}\right)}$

converged towards a value of $2.1( \pm 0.7)$. This backscatter ratio was used as the reference value for all measurements at $1064 \mathrm{~nm}$. Since the lidar system was designed for high altitude measurement, the Rayleigh signal at 1064 reaches up to more that $30 \mathrm{~km}$, which implies that the Rayleigh return signal at $1064 \mathrm{~nm}$ in the height range between 6 and $8 \mathrm{~km}$, is strong enough to ensure that this method is reliable.

In contrast to the extinction coefficient, the determination of the backscatter coefficients is based on the ratio of the Raman and the Rayleigh/Mie return signal. Thus, it can be applied also at altitudes where the laser beam and the telescope field-of-view do not fully overlap, i.e. below $1 \mathrm{~km}$. The extinction coefficient, needed for the extinction correction in Eq. (4), is extrapolated from the measurement at $607 \mathrm{~nm}$ to 355 and $1064 \mathrm{~nm}$ with the chosen $k$ value. At altitudes below $1 \mathrm{~km}$, where the extinction cannot be measured, it is assumed to be constant.

\subsection{Error discussion}

The error of the extinction coefficient is mainly determined by the statistical error of the Raman return signal. This error is assumed to be the square root of the absolute count rate and is calculated via the law of error propagation to the error in the extinction coefficient. As Ansmann et al. (1992) pointed out, a rapid change in the aerosol extinction coefficient during the averaged period induces a significant error in the mean extinction coefficient. To avoid such errors, only periods with approximately constant aerosol backscatter signals have been averaged. The error of the backscatter coefficient is mainly determined by the two factors:

(1) The chosen reference height and the chosen aerosol backscatter coefficient at this altitude (we chose zero for 355 and $532 \mathrm{~nm}$ ). The error of the calibration procedure for $1064 \mathrm{~nm}$, as described above, is determined by the standard deviation of the mean backscatter ratio $(2.1 \pm 0.7)$ and was included in the calculation via the law of error propagation. 


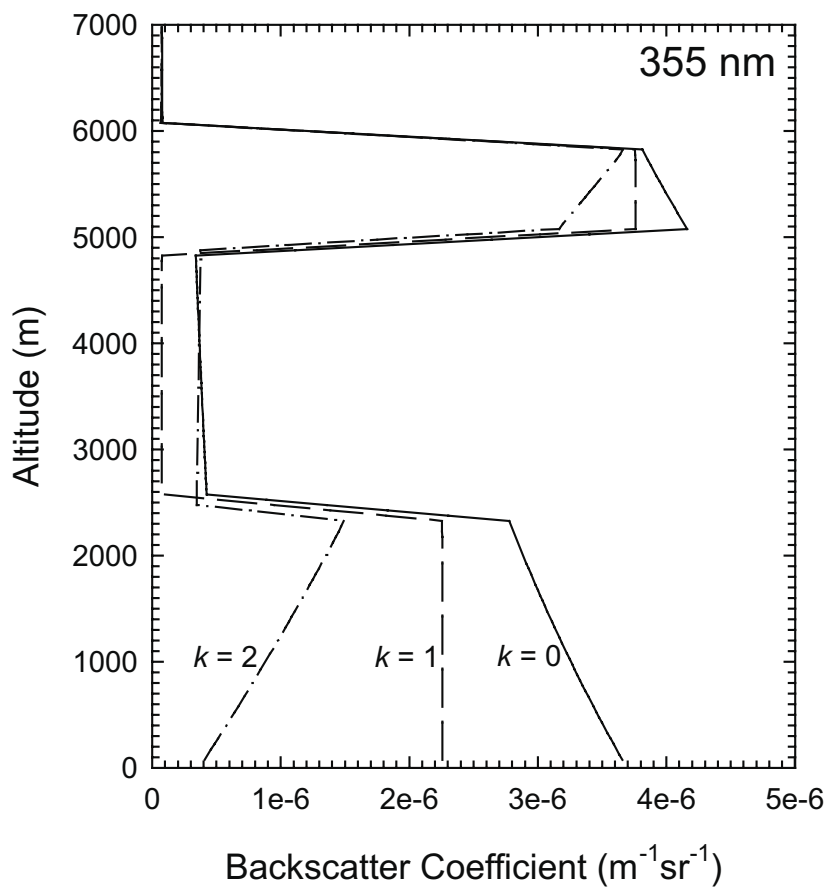

Fig. 2. Backscatter coefficient at $355 \mathrm{~nm}$, calculated from synthetic data using Eq. (4), with $k$ values of 2, 1, and 0 . The curve labelled " $k=1$ " represents the input data. The difference in the boundary layer can be more than $100 \%$.

(2) The calculation of the backscatter coefficient needs the extinction coefficient as an input (see Eq. 4). Since no Raman signals are available for 355 and $1064 \mathrm{~nm}$, the extinction coefficient measured at 532 is extrapolated with the chosen $k$ value, which introduces an additional uncertainty. To assess this uncertainty, backscatter profiles at 355 and $1064 \mathrm{~nm}$ were calculated using different $k$ values for the necessary interpolation. Figure 2 gives an example for a calculation of the backscatter coefficient from simulated data (with $k=1$ ) at $355 \mathrm{~nm}$, using $k$ values of 0 and 2. Deviations from the initial profile can be more than $100 \%$. At $1064 \mathrm{~nm}$, this effect is much smaller.

Generally, the resulting errors from both error sources exceed the statistical uncertainty by far. As mentioned above, the extinction coefficient is assumed to be constant below the lowest measured value (around $1 \mathrm{~km}$ ), which causes an additional error, especially if the boundary/residual layer height is very low. Although adjustable neutral density filters are placed in front of the photomultiplier tubes, it could not always been avoided that the photomultiplier used in the $1064 \mathrm{~nm}$ channel is overloaded by the strong backscatter signal from the boundary/residual layer. This signal-induced error causes break-down of the signal immediately above the altitude where the overload occurs, while at higher altitudes it leads to excess signal.

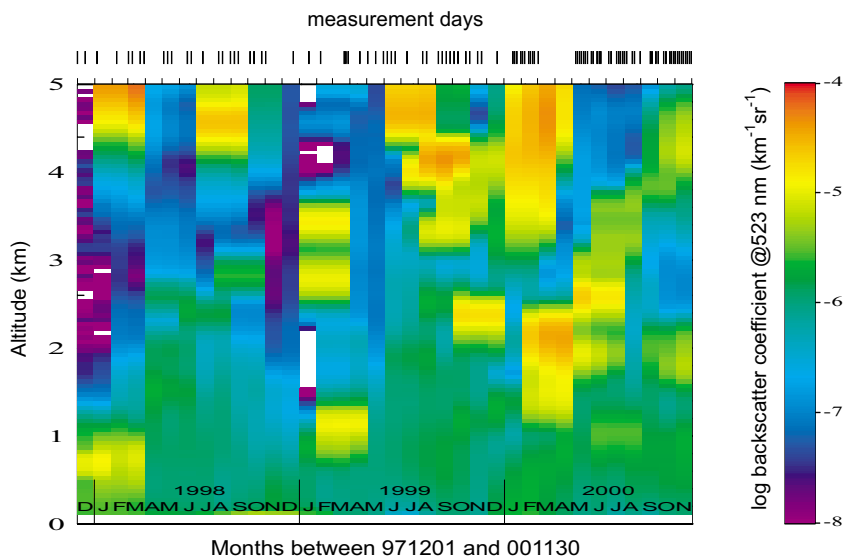

Fig. 3. Annual cycle of aerosol backscatter coefficients at $532 \mathrm{~nm}$ for all measurement days. Shown are monthly values, smoothed with a running mean over three months.

\subsection{Measurement schedule}

Regular measurements at a fixed time schedule are performed since 1 December 1997. For the usage of the Raman technique, the schedule includes one measurement each Monday after sunset (after 1 January 2000, also Thursday after sunset) with a time window of up 4 hours after sunset. In total, of 205 possible measurement days, on 102 days measurements have been performed. This corresponds to a percentage of $49.8 \%$. On the other days, is was either raining or the possibility for rain was too high. On 49 days (23.9\%), no clouds were present below $5 \mathrm{~km}$. These days are attributed as "clear" days and will be used for the further aerosol analysis, in order to separate cloud top height and residual layer height, and to assure that only aerosol properties are discussed.

\section{Results}

\subsection{Backscatter coefficients and residual layer heights}

Figure 3 shows the annual cycle of the aerosol backscatter coefficient at $532 \mathrm{~nm}$ for all measurement days. Shown are monthly mean values, smoothed with a linear running mean over 3 months. On the upper scale, the measurement days are indicated. Figure 4 gives the annual cycle for the "clear" days (no clouds below $5 \mathrm{~km}$ ). The time period displayed in both Figs. 3 and 4 is 1 December 1997 until 30 November 2000. The figures reveal an annual variability of the residual layer height between 800 and $3000 \mathrm{~m}$, with a minimum in winter and a maximum in summer. The actual time when the maximum is reached varies from year to year: In 1999 , the maximum is reached later than during the other 2 years. For the following analysis, the residual layer height was defined as that altitude where the aerosol backscatter coeffi- 

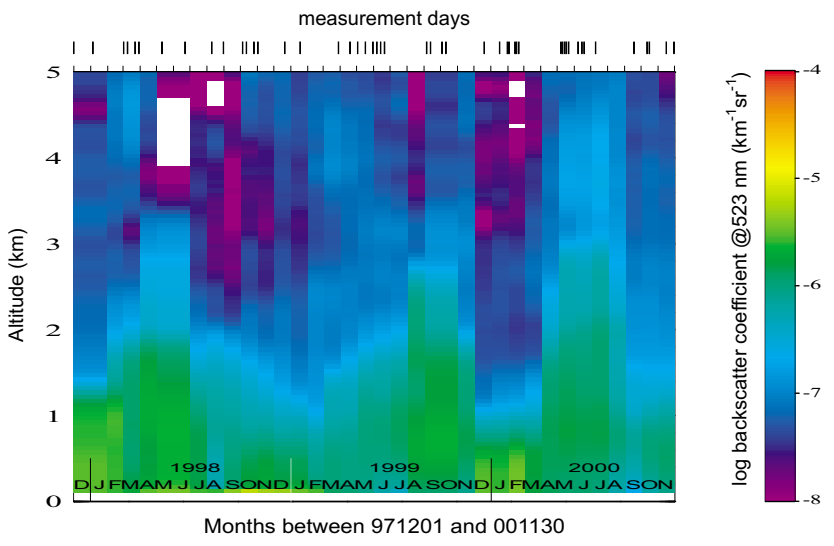

Fig. 4. Annual cycle of aerosol backscatter coefficients $(532 \mathrm{~nm})$, cloudless days only. Shown are monthly mean values, smoothed with a running mean over three months. Data gaps of two months have been filled by taking the neighboring value (e.g. the value for July 1999 is taken from June 1999). White areas indicate values below the detection limit.

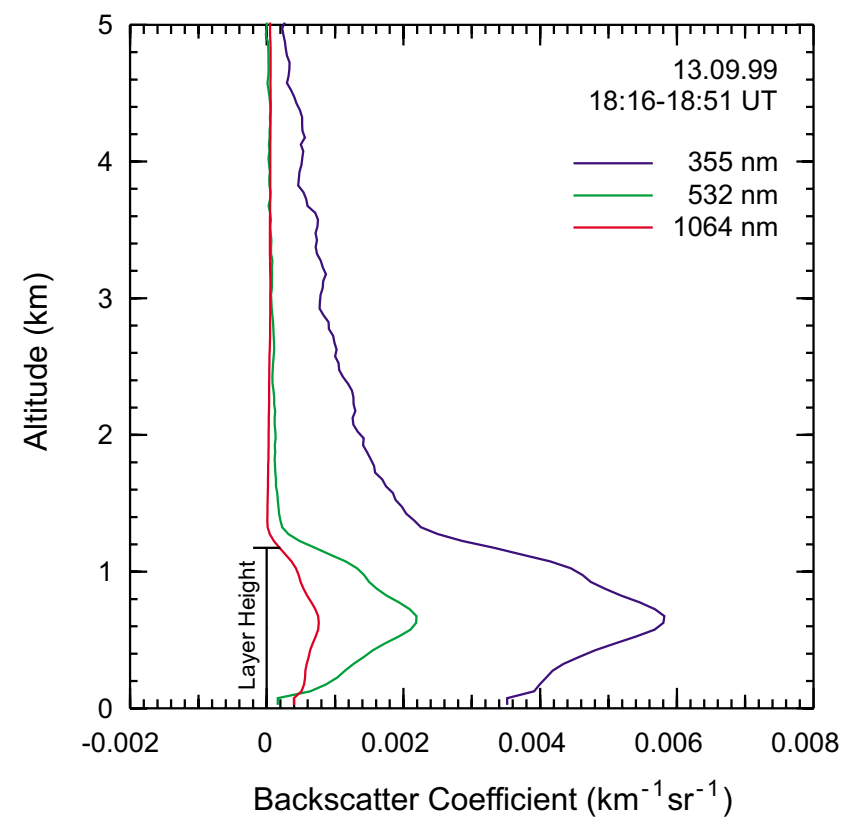

Fig. 5. Illustration of the definition of the residual layer height used in this work: The upper end of the layer is defined as that altitude $z$ where the mean backscatter coefficient decreases to half of the mean value between the lowest measurement level and $z$. To determine the residual layer height, the data measured at $532 \mathrm{~nm}$ have been used.

cient $(532 \mathrm{~nm})$ decreased to $50 \%$ of the mean value below, as shown in Fig. 5. Figure 6 shows the annual cycle of the residual layer height for the "clear" days (corresponding to Fig. 4), as three-year monthly averages. A least-squares fit

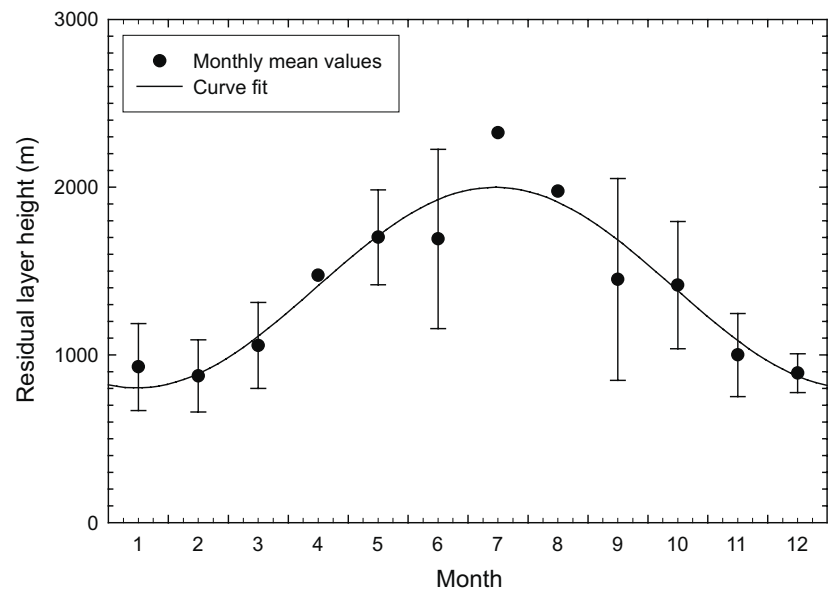

Fig. 6. Annual cycle of the monthly mean residual layer height, inferred from the backscatter coefficient at $532 \mathrm{~nm}$. The data points represent monthly mean values averaged over the 3 years. The bars represent standard deviations. Points with no bars represent the only measurement in this month. Also shown is a least-squares fit of the function $y=y_{0}+\sin ((2 p / b) x+c)$, with the constraint that $b=12$ months.

of the function

$y=y_{0}+a \sin \left(\frac{2 \pi}{b} x+c\right)$,

with the constraint that the oscillation period $b$ is 12 months, is also shown, indicating that the average maximum height of the residual layer (around mid of July) is about $2000 \mathrm{~m}$, while the average minimum height (mid of January) is $850 \mathrm{~m}$. As mentioned before, the residual layer during nighttime is the remainder of the PBL during daytime. It is therefore interesting to compare our data with daytime lidar measurements. Available data from other stations in the German Lidar Network, where daytime measurements of the boundary layer heights have been performed, are from Hamburg and Munich (Bösenberg et al., 2001a, Matthias and Bösenberg, 2001). These data show similar features: At Hamburg, about $200 \mathrm{~km}$ away from Kühlungsborn, the mean PBL height for the years 1998-2000 ranges between $900 \mathrm{~m}$ above ground in winter and $2000 \mathrm{~m}$ in summer. At Munich, at (540 $\mathrm{m}$ asl), the average boundary layer height for the years 1998-2000 varies between $450 \mathrm{~m}$ above ground in winter and $1700 \mathrm{~m}$ in summer. The excellent agreement between the average PBL height at Hamburg and the residual layer height at Kühlungsborn indicates that sampling of the residual layer after sunset is representative also for the planetary boundary layer, at least for marine environments. Note that the afternoon measurements at Munich show lower PBL heights. Apparently differences in the orography and geographical situation contribute more to the variation of the boundary layer height that the difference between afternoon and after-sunset sampling. The physical properties of the aerosol particles, however, may be 


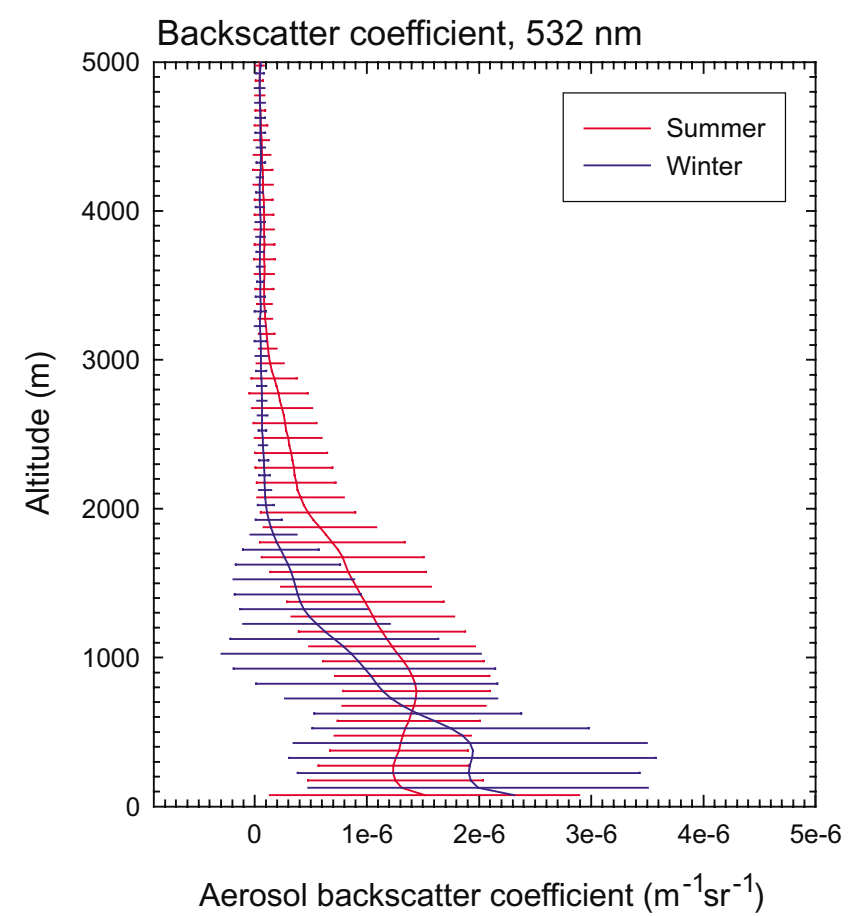

Fig. 7. Vertical profiles of the backscatter coefficient at $532 \mathrm{~nm}$, separately averaged for summer (April through September) and winter (October through March).

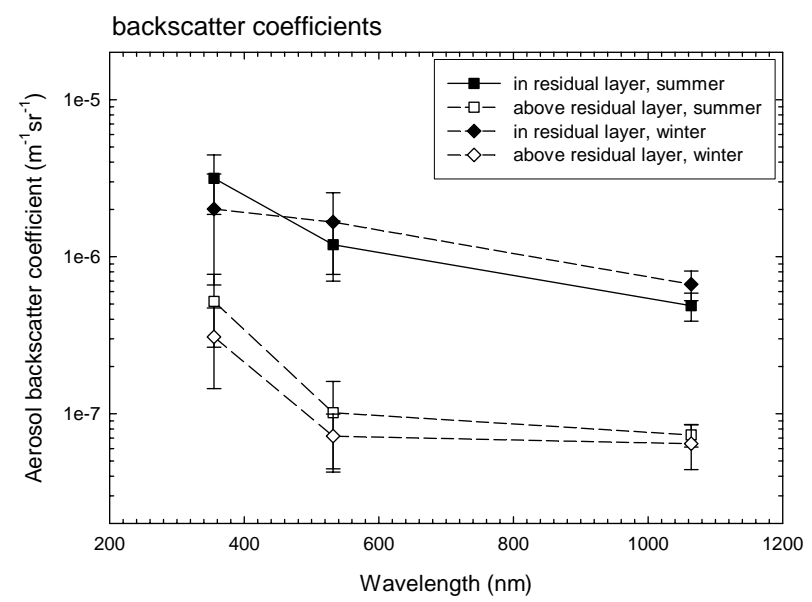

Fig. 8. Spectral dependence of mean backscatter coefficients inside and above the residual layer, averaged separately for summer (April through September) and winter (October through March).

significantly altered due to temperature and relative humidity differences between daytime and nighttime.

Figure 7 gives the vertical profiles of the backscatter coefficient at $532 \mathrm{~nm}$, where summer (April through September) and winter (October through March) were averaged separately. The maximum of the backscatter coefficient during summer appears at higher altitudes than in winter, and the

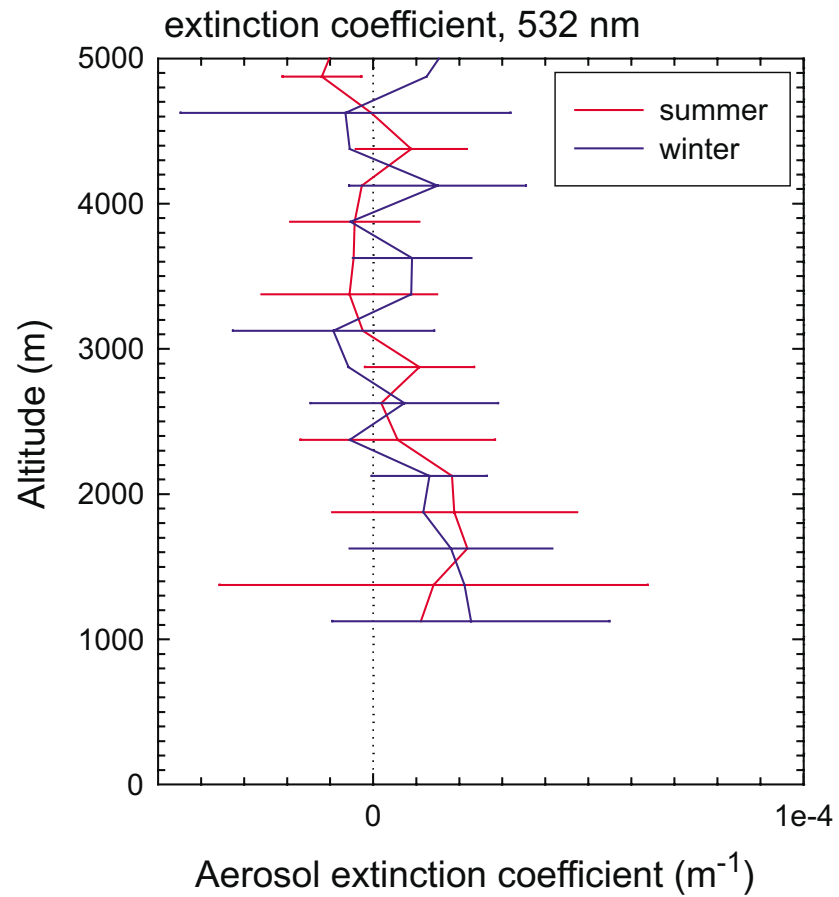

Fig. 9. Vertical profiles of the extinction coefficient at $532 \mathrm{~nm}$, separately averaged for summer (April through September) and winter (October through March).

highest values of the backscatter coefficients are reached during the winter months at the lowest 500 meters. This may be explained by the low convection during winter nights, where inversion conditions occur frequently and prevent the exchange with the free troposphere to a larger extend than in summer. The mean values, in and above the residual layer, with their standard deviations are summarized in Table 2 and plotted vs. wavelength in Fig. 8. Inside the residual layer, higher values in summer than in winter are observed at 532 and $1064 \mathrm{~nm}$. However, as the indicated standard deviation values show, these differences are not significant. Inside the standard deviations, there is no marked difference in the mean wavelengths dependency between summer and winter, but it appears that the decrease of the backscatter coefficients with wavelength between 355 and $532 \mathrm{~nm}$ above the residual layer is much steeper that inside. Since different aerosol types from different origins may contribute to this observation, the question of wavelength dependency and aerosol type will be discussed in detail in Sect. 3.3, where the results of a backtrajectory analysis are presented.

\subsection{Extinction coefficients, aerosol optical depths, and lidar ratios}

Figure 9 shows the vertical profiles of the extinction coefficient at $532 \mathrm{~nm}$, averaged separately for summer and winter, with bars denoting the standard deviation. The measurements do not cover the whole residual layer, since the 
Table 2. Mean values of backscatter and extinction coefficients, optical depths and lidar ratios in and above the residual layer

\begin{tabular}{lllllll}
\hline & $\bar{\beta}_{355 \mathrm{~nm}}\left(\mathrm{~m}^{-1} \mathrm{sr}^{-1}\right)$ & $\bar{\beta}_{532 \mathrm{~nm}}\left(\mathrm{~m}^{-1} \mathrm{sr}^{-1}\right)$ & $\bar{\beta}_{1064 \mathrm{~nm}}\left(\mathrm{~m}^{-1} \mathrm{sr}^{-1}\right)$ & $\bar{\alpha}_{532 \mathrm{~nm}}\left(\mathrm{~m}^{-1}\right)$ & $\overline{\mathrm{AOD}}_{532 \mathrm{~nm}}$ & $\overline{\mathrm{LR}}_{532 \mathrm{~nm}}(\mathrm{sr})$ \\
\hline In residual layer & & & & & & \\
Summer & $(3.2 \pm 1.3) \times 10^{-6}$ & $(1.2 \pm 0.5) \times 10^{-6}$ & $(4.9 \pm 1.0) \times 10^{-7}$ & - & - & - \\
Winter & $(2.0 \pm 1.4) \times 10^{-6}$ & $(1.7 \pm 0.9) \times 10^{-6}$ & $(6.7 \pm 1.4) \times 10^{-7}$ & - & - & \\
Above residual layer & & & & & & \\
Summer & $(5.2 \pm 2.5) \times 10^{-7}$ & $(1.8 \pm 0.6) \times 10^{-7}$ & $(7.3 \pm 1.2) \times 10^{-8}$ & $(0.5 \pm 2.8) \times 10^{-6}$ & $(0.3 \pm 1.0) \times 10^{-2}$ & $5 \pm 28$ \\
Winter & $(3.1 \pm 1.6) \times 10^{-7}$ & $(7.2 \pm 2.7) \times 10^{-8}$ & $(6.5 \pm 2.0) \times 10^{-8}$ & $(4.9 \pm 2.4) \times 10^{-6}$ & $(1.5 \pm 1.0) \times 10^{-2}$ & $68 \pm 42$ \\
\hline
\end{tabular}

lower measurement height of the lidar system is $1000 \mathrm{~m}$. The scattering of the extinction coefficients is very large, with the mean values scattering around zero above an altitude of $2.5 \mathrm{~km}$. Differences between summer and winter are not recognizable within the error limits. Mean values of the extinction coefficients as well as of the aerosol optical depth (AOD) are given in Table 2. These values describe the region between the upper edge of the residual layer and the 5 -km altitude level. The AOD values of $(0.3 \pm 1.0) \times 10^{-2}$ for summer and $(1.5 \pm 1.0) \times 10^{-2}$ for winter are comparable to the value of $1.2 \times 10^{-2}$, which is obtained from the Global Aerosol Data Set (GADS, Koepke et al., 1997, Hess et al., 1998), and imply that the contribution of the middle free troposphere (well below the tropopause but above the boundary/residual layer) on cloudless days can almost be neglected when discussing total AOD. AOD values over Central Europe at $555 \mathrm{~nm}$, obtained from satellite data, range between 0.1 and 0.6 (Robles Gonzales et al., 2000). AOD values obtained for the planetary boundary layer at the Atlanctic coast of the U. S. at $450 \mathrm{~nm}$ are in the same order of magnitude (Hartley et al., 2000). Due to the large variations especially in the extinction coefficient, the standard deviation of the mean lidar ratio above the PBL (Table 2) is more than $100 \%$ of the mean value for summer and $70 \%$ for winter, respectively. In summer, an upper limit of $33 \mathrm{sr}$ can be given, which would be in agreement with maritime aerosol (Ackermann, 1998). The mean value for winter of $68 \mathrm{sr}$ is a very reasonable value for continental aerosol (Ackermann, 1998) and also for the "free tropospheric" aerosol component in the Global Aerosol Data Set (Hess et al., 1998). However, the large variability of our data does not allow to draw further conclusions.

\subsection{Trajectory analysis}

The lidar station Kühlungsborn is located at the southern shore of the Baltic Sea, west $(30 \mathrm{~km})$ of the city of Rostock, and east $(150 \mathrm{~km})$ of the city of Hamburg. Thus, we would expect the aerosol properties to be dependent on the wind direction. To obtain information about the origin of the air masses, the three-dimensional backward trajectories pro-
Table 3. Results of the trajectory cluster analysis. Clusters containing only one trajectory were not included in the data analyis

\begin{tabular}{llll}
\hline Level & Cluster & \# of Trajectories in cluster & Percentage \\
\hline $975 \mathrm{hPa}$ & 1 & 25 & 56.8 \\
& 2 & 9 & 20.0 \\
& 3 & 5 & 11.1 \\
& 4 & 6 & 13.3 \\
$700 \mathrm{hPa}$ & 1 & 32 & 69.6 \\
& 2 & 12 & 26.1 \\
& 3 & 1 & 2.2 \\
& 4 & 1 & 2.2 \\
\hline
\end{tabular}

vided by the German Weather Service (DWD) were analysed by means of cluster analysis. The analysis was performed for trajectory arrival heights above Kühlungsborn of $975 \mathrm{hPa}$ (corresponding to $300 \mathrm{~m}$, certainly in the PBL (daytime) or the residual layer (nightime)) and $700 \mathrm{hPa}$ (corresponding to $3000 \mathrm{~m}$, always above the PBL/residual layer). Out of the 49 "clear" measurement days, 45 trajectories were available for the $975-\mathrm{hPa}$ level and 46 for the $700-\mathrm{hPa}$ level. The last three days prior to the arrival of the air mass above Kühlungsborn were considered. Following the scheme described in Romesburg (1990), the analysis was started with the same number of clusters as trajectories, and continued by decreasing the number of clusters by grouping the two most similar trajectories (those with the lowest square distance) into one cluster. This procedure was repeated up to that point where the sum of the square distances inside the clusters markedly increased. The resulting number of clusters is given in Table 3 . At the $700 \mathrm{hPa}$ level, the two dominating clusters contain more then $95 \%$ of all measurement days, the other two clusters contain only one trajectory each and were not used in the following analysis. At $975 \mathrm{hPa}$, four clusters were found which contained at least five trajectories. Figure 10 shows the dominating trajectory directions for both altitudes. At $700 \mathrm{hPa}$, the dominating wind direction is west. This cluster contains $69.6 \%$ of all trajectories, while the second cluster, 


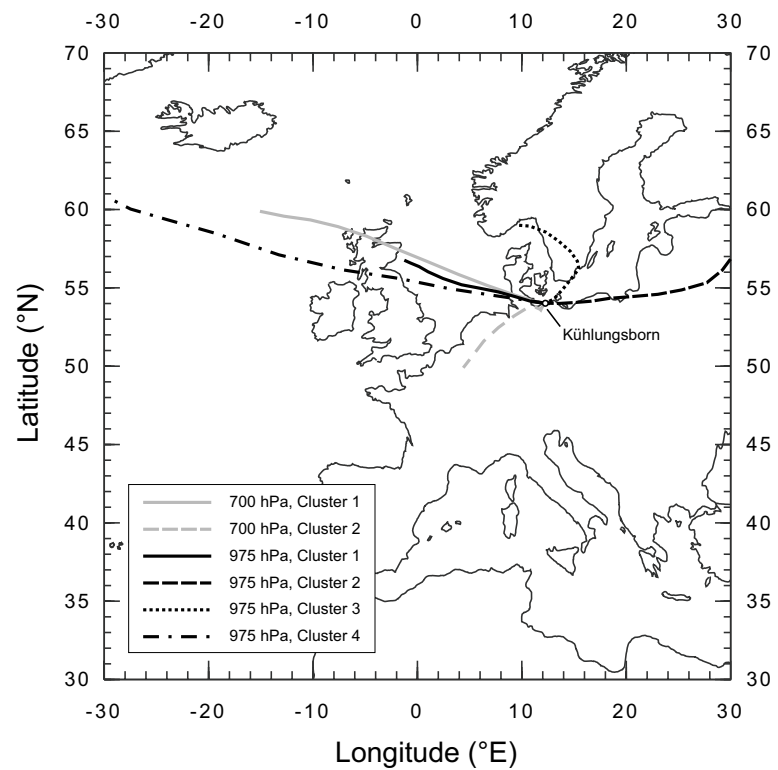

Fig. 10. Map of central Europe, showing the results of the cluster analysis of the backward trajectories arriving above Kühlungsborn $\left(54^{\circ} \mathrm{N}, 12^{\circ} \mathrm{E}\right)$ at 19:00 UT on the measurement days. Two arrival heights are shown. Gray lines: $700 \mathrm{hPa}$, black lines: $975 \mathrm{hPa}$.

coming from the south-west, contains $26.2 \%$. At $975 \mathrm{hPa}$, the western trajectories group into two clusters, characterized by high and low travelling speed. Additionally, one eastoriginating cluster and one "anti-cyclonic" cluster is present. In order to find out if a difference in the aerosol properties dependent on the origin of the air masses exists, the backscatter coefficients measured on the days contained in the individual clusters were averaged for both arrival heights. Figure 11 shows the averaged values of the backscatter coefficient at $532 \mathrm{~nm}$ along with their standard deviations: Clusters 1, 2, and 3 inside the boundary/residual layer display almost the same aerosol backscattering, although their origin is completely different. In contrast, cluster 4 (the one with high wind speed from the west) shows a markedly higher aerosol backscattering. This may be due to the higher production efficiency of dust and sea salt aerosol at higher wind speeds. For the two clusters analysed at $700 \mathrm{hPa}$, the total aerosol backscattering does not show a difference between the two clusters within the standard deviation. The right scale in Fig. 11 is expanded by factor of 10 compared to the left, illustrating that the aerosol backscattering (at $532 \mathrm{~nm}$ ) is by a factor of 10 lower above than inside the PBL.

\subsection{Comparison with the Global Aerosol Data Set}

Different aerosol types can be distinguished by the spectral dependence of the backscatter coefficients. In order to analyse the wavelength dependence, the averaged data from the individual clusters have been normalized to the value at $532 \mathrm{~nm}$. The result is given in Fig. 12. For clarity, the wave-

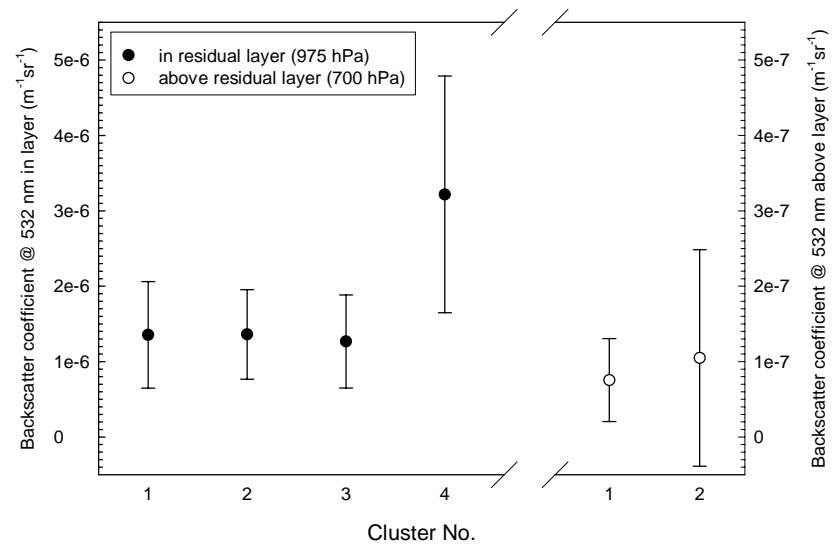

Fig. 11. Mean aerosol backscatter coefficients at $532 \mathrm{~nm}$ measured in the individual clusters given in Fig. 10. The right axis, referring to the values measured above the residual layer, is expanded by a factor of 10 compared to the left axis. Cluster $4(975 \mathrm{hPa})$ shows a markedly higher aerosol backscattering than the other 3 clusters at $975 \mathrm{hPa}$. At $700 \mathrm{hPa}$, no significant difference can be found.

lengths are shifted by $10 \mathrm{~nm}$, centred around the real value. At 975 as well as $700 \mathrm{hPa}$, the clusters do not show a significant difference in the spectral dependence, but both show a high variability, especially at $355 \mathrm{~nm}$. The mean value at $355 \mathrm{~nm}$ of cluster 4 at $975 \mathrm{hPa}$ is lower than the other three, which might fit to the assumption that the higher total aerosol backscattering of cluster 4 is due the higher content of aerosol particles generated by high wind speed (sea salt and dust) which consist of larger particles which have more neutral spectral properties. The steep gradient between 355 and $532 \mathrm{~nm}$ measured above the residual layer may suggest an underestimation of the values at $532 \mathrm{~nm}$, but the variability and measurement uncertainty at $355 \mathrm{~nm}$ are so high that the standard deviation is more than $100 \%$ of the mean value. Also shown in Fig. 12 are calculated backscatter coefficients for different aerosol types taken from the software package OPAC (Optical Properties of Aerosols and Clouds), which is based on the Global Aerosol Data Set (GADS). Both are freely available on the World Wide Web (Koepke et al., 1997, Hess et al., 1998). In this data set, the large variability of natural aerosols is reduced by the use of a dataset of typical aerosol components. The size of the individual particles in the OPAC software package is controlled by the relative humidity. We selected from this dataset those aerosol types and components which are likely to be observed at our station, for example "continental", "maritime", "free tropospheric", at their minimum and maximum relative humidities, and compared their calculated backscatter coefficients with our measurements. These backscatter coefficients were also normalized to the measured value at $532 \mathrm{~nm}$. In general, the GADS data agree very well with our data, but mostly the high variability of the measurements does not allow to distinguish between the different aerosol components. The mean values of 

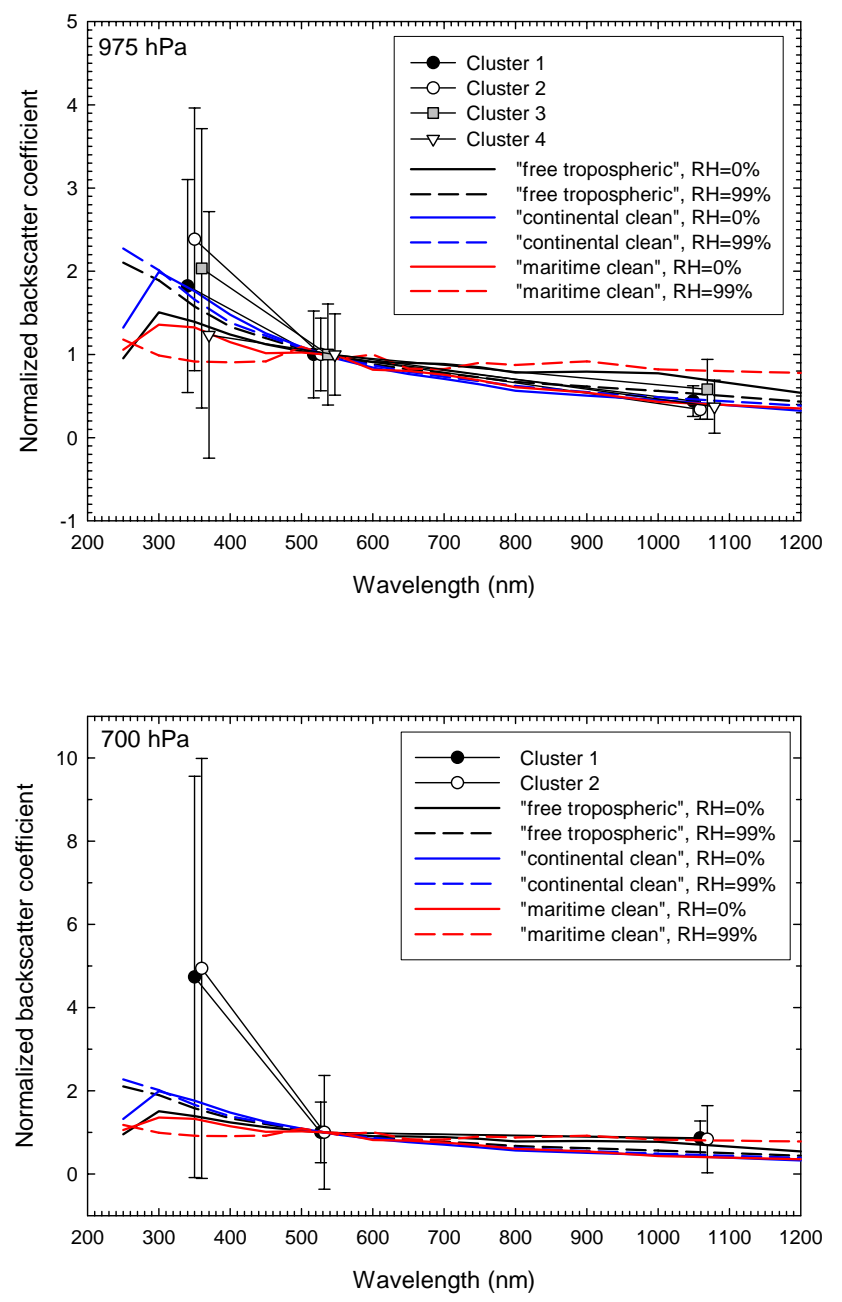

Fig. 12. Mean backscatter coefficients measured in the individual clusters given in Fig. 11, normalized to the value measured at $532 \mathrm{~nm}$. Upper panel: in the residual layer, lower panel: above the residual layer. The error bars indicate the standard deviation inside the clusters. For clarity, an offset of $10 \mathrm{~nm}$ was added to the wavelengths, centered around the real value. Also shown are selected aerosol types from the Global Aerosol Data Set (GADS).

cluster 4 (inside the residual layer) fit exactly to the aerosol type "maritime clean" in the dry state, while clusters 1,2 , and 3 are in better agreement with the continental aerosol type. For example, the "maritime clean" type at $100 \%$ relative humidity can not be brought in agreement with the values from cluster 2 , which represents the eastern trajectories. This finding appears plausible. At $700 \mathrm{hPa}$, no conclusions can be drawn due to the high variability at $355 \mathrm{~nm}$. Summarizing, we observe a slight difference between the clusters in the residual layer, but the variability inside the individual clusters is still too large to distinguish between typical aerosol components. It will be necessary to extend the number of clusters in order to reduce the variability, and to extend the data base in order to still have a representative number of trajectories in each cluster.

\section{Summary and conclusions}

We have presented three complete annual cycles of vertical aerosol profiles between 0 and $5 \mathrm{~km}$, and thereby also the annual cycle of the nighttime residual layer height. Mean values for the aerosol backscatter coefficients in and above the residual layer are given for 355,532 , and $1064 \mathrm{~nm}$. The backscatter coefficients above the residual layer are significantly lower (by about a factor of 10) than the values inside. Since our data represent night-time data (taken between sunset and midnight), they represent only the residual layer height, but not the maximum of the planetary boundary layer height, which is reached during daytime around 14:00 local solar time. The annual cycle, however, is reproduced very well by these after-sunset measurements. Furthermore, comparison with daytime PBL data at Hamburg (200 km distance) show excellent agreement between the nighttime and daytime boundary /residual layer height. The extinction coefficient could only be determined above the residual layer at $532 \mathrm{~nm}$. The inferred optical depth agrees with the value expected from the Global Aerosol Data Set. A trajectory cluster analysis performed on three-day backward trajectories did reveal a difference in the aerosol backscatter in the residual layer with respect to the wind speed. The air masses arriving with high wind speed from the west contained a markedly higher aerosol backscattering than the other air masses, whose aerosol backscattering was independent from their origin. The comparison with the Global Aerosol Data Set (GADS) showed that our measured aerosol backscatter coefficients do agree with most of the expected aerosol types. The variability inside the clusters, especially at $355 \mathrm{~nm}$, allows only a few conclusions: For example, the "maritime clean" aerosol type at $100 \%$ relative humidity can be excluded for the air masses originating from the east, which is a plausible finding. In contrast, the air masses of westerly origin travelling at high wind speed agree very well with the aerosol type "maritime clean". Future measurements and analyses will have to include the extinction coefficient at least at a second wavelength, in as well as above the residual layer, and also the daytime data to record the full boundary layer and its diurnal evolution. If these measurements can not be realized by the use of the inelastic Raman scattering, better input data for the lidar ratio are required.

Acknowledgements. The authors want to thank M. Alpers and T. Köpnick for their contribution to the aerosol lidar setup and to the measurements, J. Bösenberg for initiating the German Lidar Network and coordinating the EARLINET project, and the German Weather Service (DWD) for providing the radiosonde data and the backward trajectories.

This work was funded by the German Federal Ministry for Education, Science, Research and Technology (BMBF) within the 
Aerosol Research Program (AFS), contract No. 07AF113/0 and by the EU project EARLINET, contract No. EVR1-CT1999-40003.

\section{References}

Ackermann, J.: The extinction-to-backscatter ratio of tropospheric aerosol: A numerical study, J. Atmos. Oceanic Technol., 15, 1043-1050, 1998.

Alpers M., Eixmann, R., Höffner, J., Köpnick, T., Schneider, J., and von Zahn, U.: The Rayleigh/Mie/Raman Lidar at IAP Kühlungsborn, J. Aerosol Sci., 30, Suppl. 1, 637-638, 1999.

Ansmann, A., Riebesell, M., and Weitkamp, C.: Measurement of atmospheric aerosol extinction profiles with a Raman lidar, Opt. Lett. 15, 746-748, 1990.

Ansmann, A., Wandinger, U., Riebesell, M., Weitkamp, C., and Michaelis, W.: Independent measurement of extinction and backscatter profiles in cirrus-clouds by using a combined Raman elastic-backscatter lidar, Appl. Opt., 31, 7113-7131, 1992.

Bösenberg, J., Alpers, M., Böckmann, C., Jäger, H., Matthias, V., Trickl, T., Wandinger, U., and Wiegner, M.: A Lidar Network for the Establishment of an Aerosol Climatology, in: Proceedings of 19. ILRC, Annapolis, 1998, (Eds) Singh, U. and Ismail, S., NASA/CP-1998-207671/PT1, 23-24, 1998.

Bösenberg, J., Alpers., M., Althausen, D., Ansmann, A., Böckmann, Ch., Eixmann, R., Franke, A., Freudenthaler, V., Giehl, H., Jäger, H., Kreipl., S., Linné, H., Matthias, V., Mattis, I., Müller, D., Sarközi, J., Schneidenbach, L., Schneider, J., Trickl, T., Vorobieva, E., Wandinger, U., and Wiegner, M.: The German Aerosol Lidar Network: Methodology, Data, Analysis, MPI Meteorology Report No. 317, Hamburg, 2001a.

Bösenberg, J., Ansmann, A., Baldasano, J. M., Balis, D., Böckmann, Ch., Calpini, B., Chaikovsky, A., Flamant, P., Hagard, A., Mitev, V., Papayannis, A., Pelon, J., Resendes, D., Schneider, J., Spinelli, N., Trickl, Th., Vaughan, G., Visconti, G., and Wiegner, M.: EARLINET: A European Aerosol Research Lidar Network, in Laser Remote Sensing of the Atmosphere. Selected Papers of the $20^{\text {th }}$ International Laser Radar Conference, Edition Ecole Polytechnique, Palaiseau, (Eds) Dabas, A., Loth, C., and Pelon, J., 155-158, 2001b.

Fernald, F. G.: Analysis of atmospheric lidar observations: some comments, Appl. Opt. 23, 652-653, 1984.
Ferrare, R. A., Melfi, S. H., Whiteman, D. N., Evans, K. D., and Leifer, R.: Raman lidar measurements of aerosol extinction and backscattering 1. Methods and comparisons, J. Geophys. Res., 103, 19663-19672, 1998.

Grund, C. J. and Eloranta, E. W.: University of Wisconsin high spectral resolution lidar, Opt. Eng., 30, 6-12, 1991.

Gutkowicz-Krusin, D.: Multiangle lidar performance in the presence of horizontal inhomogeneities in atmospheric extinction and scattering, Appl. Opt., 32, 3266-3272, 1993.

Hartley, W. S., Hobbs, P. V., Ross, J. L., Russell, P. B., and Livingston, J. M.: Properties of aerosols aloft relevant to direct radiative forcing off the mid-Atlantic coast of the United States, J. Geophys. Res., 105, 9859-9885, 2000.

Hess, M., Koepke, P., and Schult, I.: Optical properties of aerosols and clouds: The software package OPAC, Bull. Amer. Meteor Soc., 79, 831-844, 1998

Klett, J. D.: Stable analytic inversion solution for processing lidar returns, Appl. Opt., 20, 211-220, 1981.

Klett, J. D.: Lidar inversion with variable backscatter/extinction ratios, Appl. Opt., 24, 1638-1643, 1985.

Koepke, P., Hess, M., Schult, I., and Shettle, E. P.: Global Aerosol Data Set, MPI for Meteorology Report No. 243, Hamburg, 1997.

Matthias, V. and Bösenberg, J.: Routine Observation of Aerosol Extinction Profiles at Hamburg: Statistical Evaluation, in Laser Remote Sensing of the Atmosphere. Selected Papers of the $20^{t h}$ International Laser Radar Conference, Edition Ecole Polytechnique, Palaiseau, (Eds) Dabas, A., Loth, C., and Pelon, J., 223227, 2001.

Penner, J., Hegg, D., and Leaitch, R.: Unraveling the role of aerosols in climate change, Environ. Sci. Technol., 35, 332A340A, 2001.

Robles Gonzales, C., Veefkind, J. P., and de Leeuw, G.: Aerosol optical depth over Europe in August 1997 derived from ATSR-2 data, Geophys. Res. Lett., 27, 955-958, 2000.

Romesburg, H. Ch.: Cluster analysis for researchers, R. E. Krieger Publishing, Malabar, Florida, pp. 335, 1990.

Sasano, Y., Browell, E. V., and Ismail, S.: Error caused by using a constant extinction/backscattering ratio in the lidar solution, Appl. Opt., 24, 3929-3932, 1985.

Seinfeld, J. H., and Pandis, S. N.: Atmospheric Chemistry and Physics, Chapter 22, John Wiley and Sons, Inc, New York, 11131192, 1998. 